\title{
ANALISIS TINGKAT KEPUASAN PASIEN TERHADAP PELAYANAN POLIKLINIK EMBUN PAGI RSUP DR. M. DJAMIL PADANG DENGAN METODE IMPORTANCE PERFORMANCE ANALYSIS
}

\author{
MUTIARA LAILA RAMADHANY, YUDIANTRI ASDI, HAZMIRA YOZZA \\ Program Studi Matematika, \\ Fakultas Matematika dan Ilmu Pengetahuan Alam, Universitas Andalas, \\ Kampus UNAND Limau Manis Padang, Indonesia, \\ moet_pearl@yahoo.co.id
}

\begin{abstract}
Abstrak. Kepuasan pelanggan atau konsumen merupakan salah satu indikator untuk mengukur kualitas layanan dalam suatu bentuk pelayanan, baik pelayanan barang maupun jasa. Dalam penelitian ini digunakan metode Importance Performance Analysis (IPA) untuk melihat tingkat kepuasan pasien Poliklinik Embun Pagi terhadap indikatorindikator pelayanan jasa yang diberikan. Penelitian ini bertujuan untuk mengetahui sejauh mana pasien merasakan puas terhadap pelayanan yang diberikan Poliklinik Embun Pagi RSUP M. Djamil Padang dan untuk mengetahui pelayanan-pelayanan yang sudah memenuhi kriteria kepuasan pasien, serta pelayanan-pelayanan yang perlu ditingkatkan dan dipertahankan. Dari hasil penelitian secara umum pasien telah merasa puas dengan pelayanan yang diberikan oleh pihak Poliklinik Embun Pagi RSUP M. Djamil Padang. Hal ini terlihat dari nilai Customer Satisfaction Index (CSI) sebesar 78.14\%. Namun itu masih belum maksimal, sehingga perlu ditingkatkan lagi agar pasien lebih merasa puas dengan pelayanan Poliklinik Embun Pagi. Pelayanan yang harus segera ditingkatkan adalah fasilitas tempat parkir.

Kata Kunci: Kepuasan Pelanggan, Customer Satisfaction Index, Importance Performance Analysis
\end{abstract}

\section{Pendahuluan}

Di Indonesia terdapat banyak rumah sakit, sehingga masyarakat memiliki banyak opsi untuk memilih rumah sakit. Pada umumnya masyarakat akan cendrung memilih rumah sakit yang memiliki fasilitas yang lengkap dan memberikan pelayanan yang terbaik bagi mereka. Dari sisi inilah setiap rumah sakit hendaknya berorientasi pada kepuasan pasien untuk dapat bersaing dengan rumah sakit lain.

Rumah Sakit Umum Pusat (RSUP) M. Djamil merupakan salah satu rumah sakit besar yang terletak di Kota Padang, Provinsi Sumatera Barat, yang pengelolaannya dipegang oleh pemerintah. Rumah sakit ini terdiri dari beberapa instansi pendukung yang disesuaikan pada fungsinya masing-masing. Salah satu instansi pendukung di RSUP M. Djamil adalah Poliklinik Embun Pagi, yang menyediakan pelayanan khusus Dokter Spesialis.

Dalam memberikan jasa kepada pelanggannya, Poliklinik Embun Pagi RSUP M. Djamil Padang harus memperhatikan beberapa indikator pelayanan yang akan mempengaruhi tingkat kepuasan pelanggan. Ada indikator yang harus dipertahankan, indikator yang harus ditingkatkan kinerjanya dan ada indikator yang menjadi prioritas sehingga harus diperhatikan oleh Poliklinik Embun Pagi. 
Untuk merangking beberapa indikator pengukuran kualitas jasa dan mengidentifikasi tindakan yang diperlukan dapat digunakan metode Importance Performance Analysis (IPA). Dalam metode ini diperlukan pengukuran tingkat kesesuaian terhadap beberapa indikator yang merujuk pada pelayanan jasa yang diberikan, guna untuk mengetahui seberapa besar pelanggan merasa puas terhadap kinerja perusahaan dan seberapa besar penyedia jasa memahami yang diinginkan oleh konsumen terhadap jasa yang diberikan.

\section{Tinjauan Pustaka}

\subsection{Uji Validitas dan Reliabilitas}

Validitas adalah suatu ukuran yang menunjukkan tingkat kevalidan atau kesahihan suatu instrumen, atau dengan kata lain sejauh mana ketepatan dan kecermatan suatu alat ukur dalam melakukan fungsinya. Berdasarkan [8], uji validitas dilakukan dengan menghitung koefisien korelasi $\left(r_{x y}\right)$ yang dapat dihitung dengan persamaan:

$$
r_{x y}=\frac{n \sum_{i=1}^{n} x_{i j} y_{i}-\left(\sum_{i=1}^{n} x_{i j}\right)\left(\sum_{i=1}^{n} y_{i}\right)}{\sqrt{n \sum_{i=1}^{n} x_{i j}{ }^{2}-\left(\sum_{i=1}^{n} x_{i j}\right)^{2}} \sqrt{n \sum_{i=1}^{n} y_{i}^{2}-\left(\sum_{i=1}^{n} y_{i}\right)^{2}}}
$$

dengan:

$$
\begin{aligned}
x_{i j} & =\text { skor item responden ke- } i \text { pada indikator ke- } j \\
y_{i} & =\text { skor total responden ke- } i \\
n & =\text { banyak responden }
\end{aligned}
$$

Hipotesis yang digunakan dalam uji ini yaitu

$$
\begin{aligned}
& H_{0}: \rho_{x y}=0 \text { (indikator tidak valid) } \\
& H_{1}: \rho_{x y} \neq 0 \text { (indikator valid) }
\end{aligned}
$$

Statistik uji yang digunakan untuk menguji hipotesis tersebut adalah

$$
t_{\text {hitung }}=\frac{r_{x y} \sqrt{n-2}}{\sqrt{1-r_{x y}^{2}}}
$$

Jika nilai statistik uji $\left(\left|t_{\text {hitung }}\right|\right)$ lebih besar dari nilai $t_{\frac{\alpha}{2}, d b}$ maka tolak $H_{0}$, sehingga indikator dikatakan valid. Jika nilai statistik uji $\left(\left|t_{\text {hitung }}\right|\right)$ lebih kecil dari nilai $t_{\frac{\alpha}{2}}, d b$ maka tidak tolak $H_{0}$ sehingga indikator dikatakan tidak valid.

Uji reliabilitas menggunakan rumus Cronbach's Alpha $\left(C_{\alpha}\right)$, yang dirumuskan sebagai berikut,

$$
C_{\alpha}=\left(\frac{k}{k-1}\right)\left(1-\operatorname{frac} \sum_{j=1}^{k} s_{x j}^{2} s_{y}^{2}\right)
$$

dengan:

$$
\begin{aligned}
k & =\text { banyaknya butir indikator } \\
s_{y}{ }^{2} & =\text { variansi skor total } \\
s_{x j}{ }^{2} & =\text { variansi skor setiap indikator }
\end{aligned}
$$

Untuk interpretasi hasil uji reliabilitas diberikan pedoman sebagai berikut, 
Tabel 2.1 Pedoman Interpretasi Terhadap Koefisien Reliabilitas

\begin{tabular}{|c|c|}
\hline Interval Nilai Reliabel & Tingkat Reliabel \\
\hline $0,00-0,19$ & Sangat Rendah \\
$0,20-0,39$ & Rendah \\
$0,40-0,59$ & Sedang \\
$0,60-0,79$ & Kuat \\
$0,80-1,00$ & Sangat Kuat \\
\hline
\end{tabular}

\subsection{Customer Satisfaction Index}

Customer satisfaction index (CSI) atau indeks kepuasan pelanggan digunakan untuk menentukan tingkat kepuasan pelanggan secara menyeluruh. Dalam menghitung nilai CSI terlebih dahulu kita menghitung nilai Mean Importance Score (MIS), Mean Satisfaction Score (MSS), Weight Factors (WF) dan Weight Score (WS) untuk masing-masing indikator, yang dirumuskan sebagai berikut:

$$
\begin{aligned}
M I S_{j} & =\frac{\sum_{i=1}^{n} y_{i j}}{n} \\
M S S_{j} & =\frac{\sum_{i=1}^{n} x_{i j}}{n} \\
W F_{j} & =\frac{M I S_{j}}{\sum_{j=1}^{k} M I S_{j}} \times 100 \% \\
W S_{j} & =W F_{j} \times M S S_{j}
\end{aligned}
$$

dengan:

$$
\begin{aligned}
y_{i j} & =\text { skor kepentingan responden ke- } i \text { indikator ke- } j \\
x_{i j} & =\text { skor kinerja responden ke- } i \text { indikator ke- } j \\
n & =\text { banyak responden } \\
k & =\text { banyak indikator }
\end{aligned}
$$

Selanjutnya dihitung nilai CSI dengan rumus berikut,

$$
C S I=\frac{\sum_{j=1}^{k} W S_{j}}{5} \times 100 \%
$$

Nilai 5 pada persamaan adalah nilai maksimal yang digunakan pada skala pengukuran. Untuk melihat seberapa jauh tingkat kepuasan pasien secara keseluruhan, diberikan pedoman sebagai berikut,

Tabel 2.2 Pedoman Interpretasi Terhadap CSI

\begin{tabular}{|c|c|}
\hline Interval Nilai CSI & Tingkat Kepuasan \\
\hline $0,00-0,34$ & Tidak Puas \\
$0,35-0,50$ & Kurang puas \\
$0,51-0,65$ & Cukup puas \\
$0,66-0,80$ & Puas \\
$0,81-1,00$ & Sangat Puas \\
\hline
\end{tabular}




\subsection{Importance Performance Analysis}

Pada metode ini akan dilihat penyebaran indikator-indikator pada diagram IPA. Diagram IPA merupakan diagram kartesius yang terbagi menjadi empat kuadran, yang mana sumbu $x$ mencerminkan tingkat kinerja dan sumbu $y$ mencerminkan tingkat kepentingan. Kemudian akan diinputkan nilai rata-rata kinerja $(\bar{x})$ dan nilai rata-rata kepentingan $(\bar{y})$ untuk setiap indikator, sehingga akan terlihat posisi masing-masing indikator dalam diagram kartesius. Berikut merupakan pembagian kuadran pada diagram kartesius,

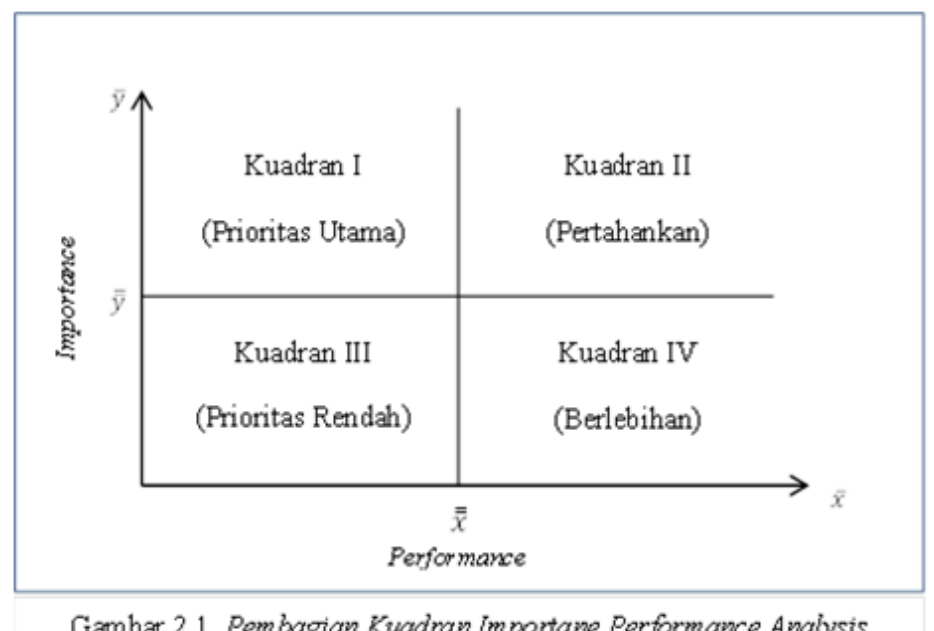

Interpretasi dari masing-masing kuadran sebagai berikut:

1. Kuadran I, wilayah yang memuat indikator-indikator dengan tingkat kepentingan yang relatif tinggi tetapi kenyataannya belum sesuai dengan apa yang diharapankan konsumen. Indikator-indikator yang masuk kuadran ini harus ditingkatkan kinerjanya.

2. Kuadran II, wilayah yang memuat indikator-indikator yang memiliki tingkat kepentingan relatif tinggi dengan tingkat kinerja yang relatif tinggi pula. Indikator yang masuk kuadran ini dianggap sebagai faktor penunjang bagi kepuasan konsumen sehingga harus tetap dipertahankan karena semua indikator ini menjadikan produk atau jasa tersebut unggul di mata konsumen.

3. Kuadran III, wilayah yang memuat indikator-indikator dengan tingkat kepentingan yang relatif rendah dan kenyataan kinerjanya tidak terlalu istimewa dan dengan tingkat kinerja yang relatif rendah. Indikator yang masuk kuadran ini memberikan pengaruh sangat kecil terhadap manfaat yang dirasakan oleh konsumen, sehingga indikator tersebut tidak perlu diprioritaskan.

4. Kuadran IV, wilayah yang memuat indikator-indikator dengan tingkat kepentingan yang relatif rendah dan dirasakan oleh konsumen terlalu berlebi- 
han dengan tingkat kinerja yang relatif tinggi. Biaya yang digunakan untuk menunjang indikator yang masuk kuadran ini dapat dikurangi agar dapat menghemat biaya pengeluaran.

\section{Hasil dan Pembahasan}

\subsection{Sampel Penelitian}

Pada penelitian ini ukuran sampel (jumlah responden) diperoleh dengan menggunakan rumus Slovin. Diperoleh informasi bahwa banyak pasien $(N)$ selama bulan Februari yaitu 953 orang pasien. Dengan demikian dapat ditentukan banyak responden $(n)$ sebagai berikut,

$$
\begin{aligned}
n & =\frac{N}{1+N e^{2}} \\
& =\frac{953}{1+953(0.1)^{2}}=90.50 \approx 91 \text { responden }
\end{aligned}
$$

Jadi banyak responden yang dibutuhkan dalam penelitian ini minimal 91 orang pasien.

\subsection{Uji Validitas dan Reliabilitas}

Uji validitas dilakukan terhadap masing-masing indikator pada tingkat kinerja dan juga tingkat kepentingan. Uji validitas dilakukan dengan menghitung nilai koefisien korelasi $\left(r_{x y}\right)$ masing-masing indikator dan kemudian dilanjutkan dengan menghitung nilai statistik ujinya $\left(t_{\text {hitung }}\right)$. Nilai $t_{\text {hitung }}$ yang diperoleh dibandingkan dengan nilai $t_{\left(\frac{\alpha}{2}, d b\right)}=2,024$ (dengan $n=40$ sehingga $d b=n-2=40-2=38$ dan $\alpha=0.05), n=40$ merupakan jumlah responden pada kuesioner uji coba. Suatu indikator dikatakan valid apabila terjadi tolak $H_{0}$ yaitu jika $\left|t_{\text {hitung }}\right|>t_{\left(\frac{\alpha}{2}, d b\right)}$.

Hasil uji validitas masing-masing indikator pada tingkat kinerja dan harapan dirangkum dalam tabel berikut. 
Tabel 3.1 Uji Validitas Indikator Kinerja dan Kepentingan

\begin{tabular}{|c|c|c|c|}
\hline \multirow{2}{*}{$\begin{array}{c}\text { Indikator } \\
\text { ke-j }\end{array}$} & Tingkat Kinerja & Tingkat Kepentingan & \multirow[b]{2}{*}{ Kesimpulan } \\
\hline & $\mathbf{t}_{\text {hitung }}$ & $\mathbf{t}_{\text {hitung }}$ & \\
\hline 1 & 2,097 & 4,948 & VALID \\
\hline 2 & 3,506 & 5,757 & VALID \\
\hline 3 & 3,652 & 3,621 & VALID \\
\hline 4 & 6,059 & 5,914 & VALID \\
\hline 5 & 5,965 & 2,364 & VALID \\
\hline 6 & 4,812 & 2,639 & VALID \\
\hline 7 & 3,058 & 6,610 & VALID \\
\hline 8 & 2,519 & 5,409 & VALID \\
\hline 9 & 12,471 & 10,839 & VALID \\
\hline 10 & 6,866 & 13,272 & VALID \\
\hline 11 & 9,977 & 9,823 & VALID \\
\hline 12 & 6,401 & 4,710 & VALID \\
\hline 13 & 6,391 & 5,608 & VALID \\
\hline 14 & 6,142 & 6,365 & VALID \\
\hline 15 & 5,291 & 10,409 & VALID \\
\hline 16 & 3,898 & 9,697 & VALID \\
\hline 17 & 9,190 & 10,980 & VALID \\
\hline 18 & 13,294 & 10,559 & VALID \\
\hline 19 & 7,018 & 12,445 & VALID \\
\hline 20 & 6,105 & 4,563 & VALID \\
\hline 21 & 2,777 & 5,336 & VALID \\
\hline 22 & 5,001 & 8,517 & VALID \\
\hline 23 & 4,248 & 7,167 & VALID \\
\hline 24 & 5,511 & 4,308 & VALID \\
\hline
\end{tabular}

Dari Tabel 3.1 terlihat bahwa nilai $t_{\text {hitung }}$ setiap indikator lebih besar dari pada nilai $t_{\left(\frac{\alpha}{2}, d b\right)}=2,024$, ini berarti tolak $H_{0}$ sehingga dapat disimpulkan semua indikator pada kuisioner dinyatakan valid.

Selanjutnya akan dilakukan uji realibilitas dengan menggunakan persamaan Cronbachs Alpha. Pada tingkat kinerja diperoleh nilai Cronbachs Alpha sebagai berikut,

$$
C_{\alpha}=\left(\frac{24}{24-1}\right)\left(1-\frac{10.9556}{49.7494}\right)=0.814 \text {. }
$$

Sedangkan pada tingkat kepentingan nilai Cronbachs Alpha yang diperoleh sebagai berikut,

$$
C_{\alpha}=\left(\frac{24}{24-1}\right)\left(1-\frac{8.9825}{71.8275}\right)=0.913 .
$$

Dari hasil perhitungan, nilai Cronbachs Alpha pada tingkat kinerja dan tingkat kepentingan terletak pada selang $0,80-1,00$, ini berarti kuesioner ini sangat reliabel untuk digunakan dalam penelitian ini.

\subsection{Customer Satisfaction Index}

Customer satisfaction index digunakan untuk mengukur kepuasan pasien secara menyeluruh dengan memperhatikan tingkat kepentingan dari indikator-indikator 
pelayanan. Untuk hasil perhitungan nilai Mean Importance Score (MIS), Mean Satisfaction Score (MSS), Weight Factors (WF) dan Weight Score (WS) dari masingmasing indikator, dirangkum pada tabel berikut,

Tabel 3.2 Perhitungan Customer Satisfaction Index (CSI)

\begin{tabular}{|c|c|c|c|c|c|}
\hline No & Indikator & $\begin{array}{c}\text { Mean } \\
\text { Importance } \\
\text { Score (MIS) }\end{array}$ & $\begin{array}{c}\text { Weight } \\
\text { Factors } \\
\text { (WS) }\end{array}$ & $\begin{array}{c}\text { Mean } \\
\text { Satisfaction } \\
\text { Score (M SS) }\end{array}$ & $\begin{array}{l}\text { Weight } \\
\text { Score } \\
\text { (WS) }\end{array}$ \\
\hline 1 & Kelayakan kondisi gedung & 4,5385 & 0,0428 & 4,1319 & 0,1767 \\
\hline 2 & Keterse diaan tempat parkir & 4,5824 & 0,0432 & 2,0440 & 0,0883 \\
\hline 3 & Kebersihan ruangan pem eriksaan & 4,3516 & 0,0410 & 3,9121 & 0,1604 \\
\hline 4 & Kondisi ruang tunggu & 4,3736 & 0,0412 & 4,1209 & 0,1698 \\
\hline 5 & Kebersihan dan kelengkapan alat-alat medis & 4,8791 & 0,0460 & 4,0549 & 0,1864 \\
\hline 6 & $\begin{array}{l}\text { Kebersihan dan kerapian dokter/peraw at dalam } \\
\text { berpakaian }\end{array}$ & 4,2088 & 0,0397 & 4,0769 & 0,1617 \\
\hline 7 & Ketersediaan pengumuman & 4,0110 & 0,0378 & 3,4945 & 0,1321 \\
\hline 8 & Kemudahan dalam prosedur administrasi & 4,3407 & 0,0409 & 4,1538 & 0,1699 \\
\hline 9 & Ketepatan jadwal pelayanan & 4,2088 & 0,0397 & 3,4066 & 0,1351 \\
\hline 10 & Keberadaan dokter di tempat & 4,2198 & 0,0398 & 2,6593 & 0,1057 \\
\hline 11 & Kesesuaian resepobat dan penyakit & 4,7033 & 0,0443 & 4,1319 & 0,1831 \\
\hline 12 & Kecepatan dalam proses pendaftaran & 4,3407 & 0,0409 & 4,0110 & 0,1641 \\
\hline 13 & $\begin{array}{l}\text { Kecepatan dan ketanggapan dokter dan peraw at } \\
\text { dalam menangani kehuhan pasien }\end{array}$ & 4,4066 & 0,0415 & 4,1538 & 0,1725 \\
\hline 14 & Kecepatan dalam mendiagnosa perryalit & 4,2747 & 0,0403 & 4,0220 & 0,1620 \\
\hline 15 & Inf orma si yang jelas dr petugas & 4,2198 & 0,0398 & 3,9231 & 0,1560 \\
\hline 16 & Kesiagaan petugas saat dibutuhkan & 4,3297 & 0,0408 & 3,6484 & 0,1489 \\
\hline 17 & Keam anan rum ah sakit dan ruang pasien & 4,6264 & 0,0436 & 4,3956 & 0,1916 \\
\hline 18 & $\begin{array}{l}\text { Kem ampuan dokter dalam mendia gnosa } \\
\text { perryakit }\end{array}$ & 4,7473 & 0,0447 & 4,4505 & 0,1991 \\
\hline 19 & Keterampilan dokter dan peraw at dalam bekerja & 4,6374 & 0,0437 & 42857 & 0,1873 \\
\hline 20 & Keramahan petugasa administrasi & 4,5824 & 0,0432 & 4,0879 & 0,1765 \\
\hline 21 & Pelayanan berurutan sesuai antrian & 4,3077 & 0,0406 & 3,9341 & 0,1597 \\
\hline 22 & $\begin{array}{l}\text { Keramahan dokter dan peraw at ssat melakukan } \\
\text { pemeriksaan kesehatan pasien }\end{array}$ & 4,4286 & 0,0417 & 4,0549 & 0,1692 \\
\hline 23 & $\begin{array}{l}\text { Kepe dulian dokter dan perawat terhadap } \\
\text { keluhan pasien }\end{array}$ & 4,3956 & 0,0414 & 42857 & 0,1775 \\
\hline 24 & Pelayanan tanpa memebedakan status & 4,4066 & 0,0415 & 4,1758 & 0,1734 \\
\hline \multicolumn{2}{|r|}{ Skortotal } & 106,1209 & & & 3,9071 \\
\hline
\end{tabular}

Kemudian dapat dihitung nilai CSI sebagai berikut,

$$
C S I=\frac{3.9071}{5} \times 100 \%=78.14 \%
$$

Nilai $C S I$ yang diperoleh berada pada interval 0,66-0,80 yang berarti secara umum pasien telah merasa puas terhadap pelayanan yang diberikan oleh pihak Poliklinik Embun Pagi RSUP M. Djamil Padang. Namun pihak Poliklinik Embun Pagi RSUP M. Djamil Padang harus meningkatkan lagi kualitas pelayanannya, agar nilai $C S I$ nya bisa mendekati $100 \%$, sehingga pasien merasa lebih puas lagi dengan pelayanan yang ada. 
102 Mutiara Laila Ramadhany dkk.

\subsection{Importance Performance Analysis}

Importance Performance Analysis (IPA) dilakukan untuk melihat penyebaran indikator-indikator pada diagram kartesius. Terlebih dahulu akan dihitung nilai rata-rata skor tingkat kinerja $\left(\bar{x}_{j}\right)$ dan rata-rata skor tingkat kepentingan $\left(\bar{y}_{j}\right)$ dari masing-masing indikator. Dengan begitu akan terbentuk titik koordinat dari masing-masing indikator $\left(\bar{x}_{j}, \bar{y}_{j}\right)$, yang kemudian nilai ini akan diplotkan ke dalam diagram kartesius. Hasil perhitungan nilai rata-rata skor tingkat kinerja $\left(\bar{x}_{j}\right)$ dan rata-rata skor tingkat kepentingan $\left(\bar{y}_{j}\right)$ dirangkum dalam Tabel 3.3 berikut.

Tabel 3.3 Rata-rata Skor Tingkat Kinerja dan Kepentingan

\begin{tabular}{|c|c|c|c|c|}
\hline \multirow[b]{2}{*}{ No. } & \multirow[b]{2}{*}{ Indikat or } & \multicolumn{2}{|c|}{ Rata-rata Skor } & \multirow[b]{2}{*}{ Titik Koordinat } \\
\hline & & Kinerja & Kepentingan & \\
\hline 1 & Kelayakan kondisi geding & 4,1319 & 4,5385 & $(4,1319 ; 4,5385)$ \\
\hline 2 & Keterse diaan tempat parkir & 2,0440 & 4,5824 & $(2,0440 ; 4,5824)$ \\
\hline 3 & Keber sihan ruangan pemeriksaan & 39121 & 4,3516 & $(3,9121 ; 4,3516)$ \\
\hline 4 & Kondsi ruang tunggu & 4,1209 & 4,3736 & $(4,1209 ; 4,3736)$ \\
\hline 5 & $\begin{array}{l}\text { Keber sihan dan kelengkapan alat-alat } \\
\text { medis }\end{array}$ & 4,0549 & 4,8791 & $(4,0549 ; 4,8791)$ \\
\hline 6 & $\begin{array}{l}\text { Keber sihan dan kerapian dokter/perawat } \\
\text { dalam berpakaian }\end{array}$ & 4,0769 & 42088 & $(4,0769 ; 4,2088)$ \\
\hline 7 & Keterse diaan pengumum an & 3,4945 & 4,0110 & $(3,4945 ; 4,0110)$ \\
\hline 8 & Kemudahan dalam prosedur admiristrasi & 4,1538 & 4,3407 & $(4,1538 ; 4,3407)$ \\
\hline 9 & Ketepatan jadwal pelayanan & 3,4066 & 42088 & $(3,4066 ; 4,2088)$ \\
\hline 10 & Keberadaan dokter di tempat & 2,6593 & 42198 & $(2,6593 ; 4,2198)$ \\
\hline 11 & Kesesuaian resepobat dan perryakit & 4,1319 & 4,7033 & $(4,1319 ; 4,7033)$ \\
\hline 12 & Kecepatan dalam proses pendaftaran & 4,0110 & 4,3407 & $(4,0110 ; 4,3407)$ \\
\hline 13 & $\begin{array}{l}\text { Kecepatan dan ketanggapan dolter dan } \\
\text { per aw at dalam m enangari kehuhan pasien }\end{array}$ & 4,1538 & 4,4066 & $(4,1538 ; 4,4066)$ \\
\hline 14 & Kecepatan dalam mendagnosa perryalkit & 4,0220 & 42747 & $(4,0220 ; 4,2747)$ \\
\hline 15 & Informasi yang jelas dr petugas & 3,9231 & 42198 & $(3,9231 ; 4,2198)$ \\
\hline 16 & Kesiagaan petugas saat dibutuhkan & 3,6484 & 4,3297 & $(3,6484 ; 4,3297)$ \\
\hline 17 & Keamanan rumah sakit dan ruang pasien & 4,3956 & 4,6264 & $(4,3956 ; 4,6264)$ \\
\hline 18 & $\begin{array}{l}\text { Kemampuan dokter dalam mendiagnosa } \\
\text { perryakit }\end{array}$ & 4,4505 & 4,7473 & $(4,4505 ; 4,7473)$ \\
\hline 19 & $\begin{array}{l}\text { Keterampilan dokter dan per awat dalam } \\
\text { bekerja }\end{array}$ & 42857 & 4,6374 & $(42857 ; 4,6374)$ \\
\hline 20 & Keramahan petugasa administrasi & 4,0879 & 4,5824 & $(4,0879 ; 4,5824)$ \\
\hline 21 & Pelayanan berưutan sesugi antrian & 3,9341 & 4,3077 & $(3,9341 ; 4,3077)$ \\
\hline 22 & $\begin{array}{l}\text { Keramahan dokter dan perawat ssat } \\
\text { melakukan pemeriksaan kesehatan pasien }\end{array}$ & 4,0549 & 4,4286 & $(4,0549 ; 4,4286)$ \\
\hline 23 & $\begin{array}{l}\text { Kepectulian dokter dan perawat terhadap } \\
\text { keluhan pasien }\end{array}$ & 4,2857 & 4,3956 & $(4,2857 ; 4,3956)$ \\
\hline 24 & Pelayanan tanpa memebedakan status & 4,1758 & 4,4066 & $(4,1758 ; 4,4066)$ \\
\hline
\end{tabular}




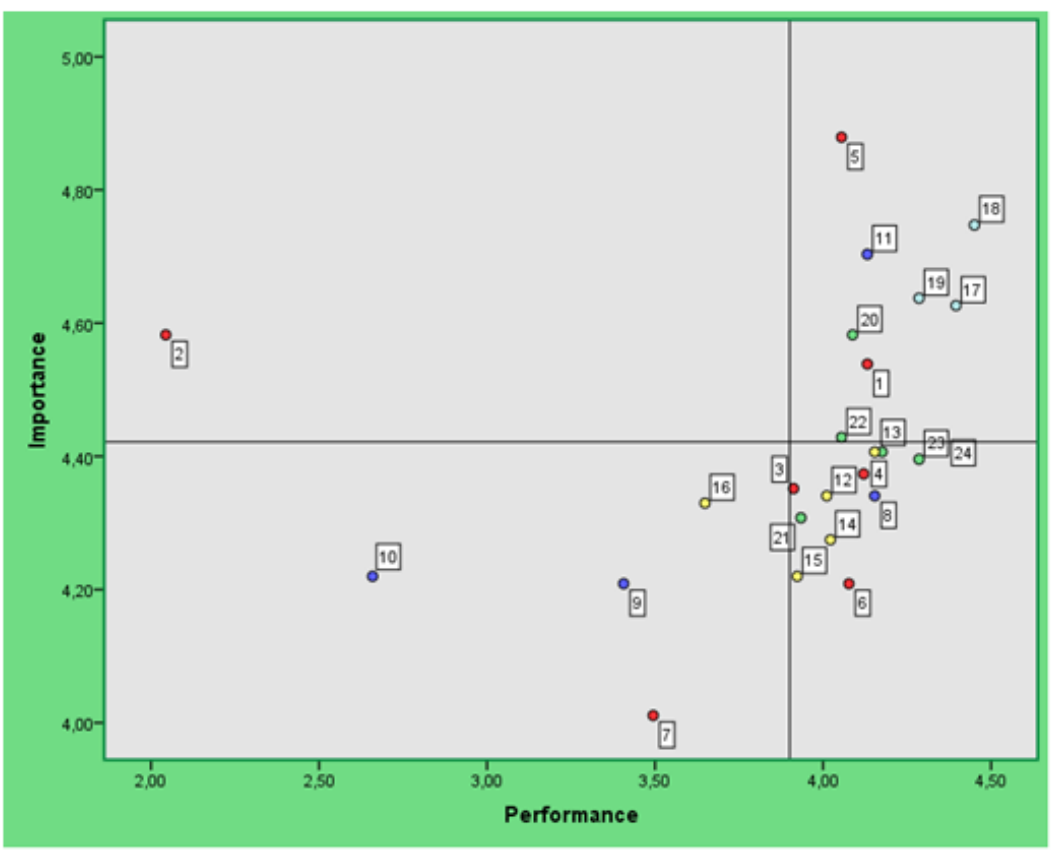

Gambar 4.1 Penyebaran Indikator pada Diagram Kartesius

Dari diagram yang terbentuk kita dapat menginterpretasikannya sebagai berikut:

1. Kuadran I menunjukkan penyebaran indikator-indikator yang harus diperhatikan dan ditingkatkan oleh pihak Poliklinik Embun Pagi RSUP M. Djamil. Karena indikator-indikator ini dianggap penting bagi pasien namun belum terlaksana dengan baik. Indikator yang tersebar dalam kuadran ini yaitu ketersediaan tempat parkir.

2. Kuadran II menunjukkan indikator-indikator yang juga dirasa penting bagi pasien dan telah terlaksana dengan baik oleh pihak Poliklinik Embun Pagi RSUP M. Djamil. Karena indikator ini dianggap penting oleh pasien, jadi indikator yang tersebar di kuadran II ini merupakan penunjang bagi kepuasan pasien sehingga harus dipertahankan.

3. Kuadran III menunjukkan indikator-indikator yang dianggap kurang penting oleh pasien dan kinerjanya pun tidak terlalu diperhatikan oleh pihak Poliklinik Embun Pagi RSUP M. Djamil. Indikator yang tersebar pada kuadran ini memberikan pengaruh sangat kecil terhadap kepuasan yang dirasakan oleh pasien.

4. Kuadran IV menunjukkan indikator-indikator yang dianggap berlebihan dalam pelaksanaannya. Karena dengan tingkat kepentingan yang relatif rendah namun dalam pelaksanaannya memberikan kepuasan yang tinggi kepada pasien. 
104 Mutiara Laila Ramadhany dkk.

\section{Kesimpulan}

Dari hasil penelitian yang dilakukan dapat disimpulkan bahwa secara umum pasien telah merasa puas dengan pelayanan yang diberikan oleh pihak Poliklinik Embun Pagi RSUP M. Djamil Padang. Hal ini terlihat dari nilai Customer Satisfaction Index sebesar 78,14\%. Namun itu masih belum maksimal sehingga perlu ditingkatkan lagi, agar pasien lebih merasa puas lagi dengan pelayanan Poliklinik Embun Pagi.

Berdasarkan hasil pengolahan yang dilakukan dengan Importance Performance Analysis (IPA), dapat diketahui indikator-indikator yang harus dibenahi dan menjadi prioritas untuk perbaikan. Indikator-indikator yang dirasa penting bagi pasien dan telah terlaksana dengan baik oleh pihak Poliklinik Embun Pagi RSUP M. Djamil harus dipertahankan. Indikator-indikator tersebut yaitu kelayakan kondisi gedung, kebersihan dan kelengkapan alat-alat medis, kesesuaian resep obat dengan penyakit, keamanan rumah sakit dan ruang pasien, kemampuan dokter mendiagnosa penyakit, keterampilan dokter dan perawat dalam bekerja, keramahan petugas administrasi serta keramahan dokter dan perawat saat melakukan pemeriksaan.

Indikator yang berada pada skala prioritas utama harus segera dibenahi, yaitu ketersediaan tempat parkir.

\section{Ucapan Terima kasih}

Penulis mengucapkan terima kasih kepada Ibu Dr. Ferra Yanuar, Ibu Dr. Maiyastri dan Bapak Dr. Dodi Devianto yang telah memberikan masukan dan saran sehingga paper ini dapat diselesaikan dengan baik.

\section{Daftar Pustaka}

[1] Hannie. 2007. Analisis Keamanan Sytem dan Kualitas Pelayanan pada PT. Vayatour dengan Metode Customer Satisfaction Index (CSI). Jurnal Mahasiswa Universitas Gunadarma. $6-8$

[2] Himawan, A. D., P. Deoranto dan D.M. Ikasari. 2013. Analisis Strategi Bauran Pemasaran Agrowisata dengan Metode Impoetance Performance Analysis dan Customer Satisfaction Index. Jurnal jurusan Teknologi Industri Pertanian, Universitas Brawijaya. 8-9

[3] Kotler, P. dan G. Armstrong. 1996. Principles of Marketing. Intermedia, Jakarta

[4] Kotler, P. dan K.L. Keller. 2007. Manajemen Pemasaran. Edisi Kedua Belas. Indeks , Jakarta

[5] Ong, J. O. dan J. Pambudi. 2014. Analisis Kepuasan Pelanggan dengan Importance Peformance Analysis di SPBU Laboratory Cibitung PT. Sucofindo (Persero). Jurnal Teknik Industri Universitas Brawijaya IX (1) : $4-6$

[6] Sugiyono. 2008. Metode Penelitian Bisnis. Alfabeta, Bandung

[7] Tjiptono, F. 2000. Manajemen Jasa. Edisi kedua. Andi Offset, Jakarta

[8] Uyanto, S.S. 2009. Pedoman Analisis Data dengan SPSS. Edisi Ketiga. Graha Ilmu, Yogyakarta

[9] Winardi. 1991. Marketing dan Perilaku Konsumen Mundur Maju. Bandung 